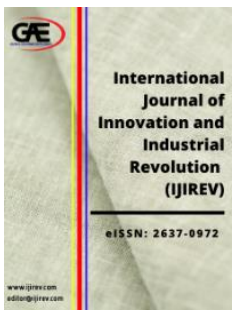

\author{
INTERNATIONAL JOURNAL OF \\ INNOVATION AND \\ INDUSTRIAL REVOLUTION \\ (IJIREV) \\ WWW.ijirev.com
}

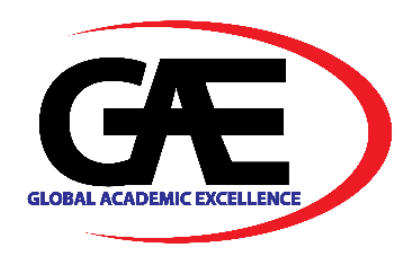

\title{
STRATEGIC CHALLENGES FOR SUCCESSFUL PROJECT MANAGEMENT IN THE ERA OF COVID-19 ENDEMIC
}

\author{
Farkhanda Naheed $^{1 *}$, Lamya AlMulla ${ }^{2}$ \\ $1 \quad$ Projects Control Engineer, Transmission Projects, DEWA, Dubai \\ Email: Farkhanda.naheed@dewa.gov.ae \\ 2 Senior Manager Transmission Projects, DEWA, Dubai \\ Email: Lamya.Almulla@dewa.gov.ae \\ 8 Corresponding Author
}

\section{Article Info:}

Article history:

Received date: 05.08 .2021

Revised date: 22.08.2021

Accepted date: 20.09.2021

Published date: 30.09 .2021

\section{To cite this document:}

Naheed, F., \& AlMulla, L. (2021). Strategic Challenges For Successful Project Management In The Era Of Covid-19 Endemic. International Journal of Innovation and Industrial Revolution, 3 (8), 31-41.

DOI: $10.35631 /$ IJIREV.38003

This work is licensed under CC BY 4.0

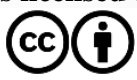

\begin{abstract}
:
In project management, strategic challenges are likely to be issues or contentions that can have a significant impact on project success. Often project success depends upon how timely and effective strategic implementations were undertaken. Nowadays, Project-based organization cultures are observing a seemingly ever-increasing pace of change and evolving with emerging new technologies. Digital technologies are impacting the dynamics of workplaces by rapidly changing competitive thinking amongst employees including their horizontal and vertical collaborations. After the recent unprecedented times during Covid 19 pandemic, the working methodologies to accommodate remote work cultures have been inculcated into the organizations. This has led to change management, accountability, and productivity determination as a more stern challenge for strategic developments. Additionally, keeping the team focussed and strategically aligned with the organizational mission and vision has become a vital project management aspect. The objective of this article is to explain the strategic challenges faced by project management in strategy implementation in project-based organizations and the possible solutions to the challenges. The ways of succeeding with these challenges effectively are to put more consideration on strategy implementation and develop new strategies to meet with future technology advancements. Moreover, Management should articulate their strategy of how to improve employee capabilities and skills in certain job positions coupled with new technology, which can enhance behavioural strategies for employees. The study will contribute further on new knowledge to the existing body of knowledge on strategy implementation challenges faced by Project management. The study also established that employees' resistance to change and lack of skills to some extent affected the implementation of strategies within the organizations. However, practicing proper change management in the organization can minimize the resistance. The knowledge gained through
\end{abstract}




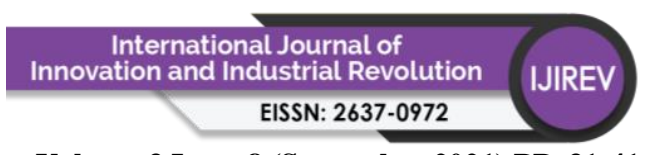

Volume 3 Issue 8 (September 2021) PP. 31-41

DOI 10.35631/IJIREV.38003

this research will thus be useful in improving the overall performance of Projects.

Keywords:

Strategic Challenges, Project Management, Change Management, Strategy Implementation, Project Based Organizations

\section{Introduction}

Organizations, leveraging project management tools and techniques, strategize and implement innovative business approaches to gain and maintain competitive strengths. There has been a growing need to align project management with the organization's strategy and performance improvement. In doing so, identifying common challenges the organization faces in project management can help us build a better future for this necessary body of knowledge. As a result, some of the main challenges that Project Managers have faced with them in the current times are summarized in this study.

Based on an extensive review of the literature, some of the main challenges for project managers include, but are not limited to, strategy implementation, behavior strategy management among employees, cooperation with emerging technologies, Effective Change Management and digitalization.

The strategic challenges of organizations and change management processes, along with problems that arise in project execution, are increasing the demand for professional experience in project management. While managing projects, project managers need to address project constraints - resources, timelines, budget, ensure proper communication, and anticipate potential risks.

Project management has been considered as the foundation of organizational strategy along with its functional approach. As organizations seek competitive advantages in today's dynamic business environments, project management proves to be the method of improving quality and work practices to improve the overall performance of the organization.

A systematic approach is required for the successful implementation of a good governance strategy that incorporates strategic planning and performance management. Therefore, implementing strategies successfully is vital for any organization. Without implementation, even the most superior strategy that seems straightforward can fail. However, transforming strategies into actions is a much more complex and strenuous task.

After the 2019 pandemic, project managers are often asked to manage projects virtually. This trend is very likely to continue into the unpredictable future and is the new normal. The Project Manager needs to adapt to this changing environment along with their approach to managing traditional project management processes. To participate in such a competitive virtual environment, project managers must be open to a new skill set and a new way of thinking. It is imperative that the project manager works on a righteous communication strategy within the remotely working teams and must manage the behavioral strategy between them along with productivity, accountability and performance management. Therefore, the project manager acts as a facilitator and needs to understand the cultural variations and potential sensitivities of 


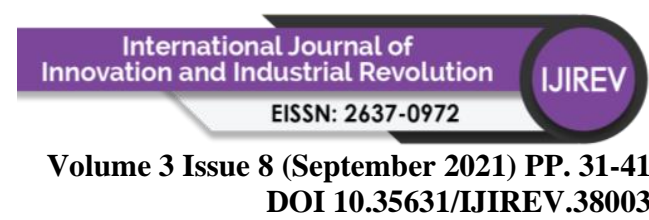

different individuals in order to attempt to achieve team alignment and coordination to cohesively perform on current and future projects. The main goal of the organization in this case is to provide a stress-free environment for the project manager and his team.

In recent times, technological advancement and digitization have an intense impact on new project management tools and techniques. As digitization is a great hope for improvement in project management since it improves decision-making and provides greater transparency in projects. On the other hand, many organizations are adapting agile as a new approach to project management. There are many specific methodologies that have grown up around agile (including SCRUM, SAFE, XP, Kanban) and each of these have their passion- ate champions, but just as there is no single roadmap for transformation, there is no one methodology that is always best. Instead, it is far more important for an organization to find its own way and develop ways working (often through prototyping the working methodology itself) that are suited to its unique context. This process may well draw on foundational principles from Agile, Lean and design thinking in order to create a scalable approach. Alongside this it is critical to understand the fundamental mind- set shifts that are involved and how we can apply these principles effectively through the organization to support transformation. Achieving a new level of organizational agility requires continuous iteration and adaptation but we also need a compelling vision and an understood organizing direction. We need to establish the parameters to understand what need to change rapidly, and what might change far more slowly. And beyond this, to understand how feedback from faster iteration can inform the slower-changing strategy. (Perkin, 2020)

Therefore, after all these advancements in project management approaches, it is necessary to have an Effective Change Management strategy that must be supported by the overall organizational vision. In defining the purpose of the change, the change objective has a clear impact on the strategy and plans required to achieve the change. The objective defines the what, why, how, when, and who. Without its objectives adequately defined, a project will run into major problems. Managers will develop their own objectives and projects will achieve inappropriate ends; resources will be committed without due analysis of their availability; and action will be carried out without taking full account of other important factors. (Morris, 1983)

\section{Literature Review}

A strategy is defined as the determination of basic long-term goals and objectives of an enterprise and the adoption of causes and actions and the allocation of resources necessary for carrying out these goals. (AD., 1996)

Strategy is the unified, comprehensive and integrated plan that relates the strategic advantage of the firm to the challenges of the environment and is designed to ensure that basic objectives of the enterprise are achieved through proper implementation process. (Glueck, 1984)

Strategic management can be defined as the art and science of formulating, implementing and evaluating cross-functional decisions that enable an organization to achieve its objective. The purpose of strategic management is to exploit and create new and different opportunities for tomorrow; long-range planning, in contrast, tries to optimize for tomorrow the trends of today. (R.David, 2007) 


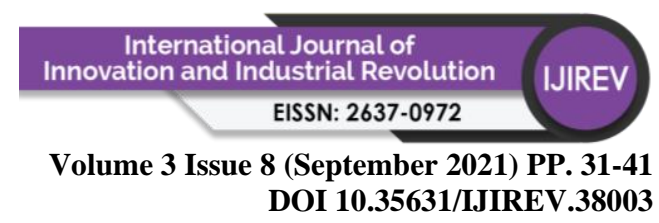

Although formulating a consistent strategy is a difficult task for any management team, making that strategy work by implementing it throughout the organization is even more difficult (Hrebiniak, 2006).It is thus obvious that strategy implementation is a key challenge for today's organizations.

Strategic and business management skills involve the ability to see the high-level overview of the organization and effectively negotiate and implement decisions and actions that support strategic alignment and innovation. (PMI USA, 2017)

According to Max McKeown, there is no guarantee that the future will turn out the way you want. Just writing a plan does not mean that the plan will happen. The world is more complex than our ability to plan, but that's part of what an effective strategist learns to accept. You learn that reacting and responding to events is just as important as planning. Progress is made when the organization moves towards strategy that learns its lessons and adapts to new opportunities. Most strategy involves change. People will have to change something they are doing to make the strategy come to life. You need to be able to translate your strategy into actions, tasks and projects. You also need to communicate the logic and of the strategy so that people get engaged with the work and are willing to help it succeed. (Mckeown, 2016)

Organizations have therefore resorted to using strategies in their planning and management processes to remain competitive (Pearce II, 2007)

Among the issues pointed out by (Hrebiniak, 2006) as overreaching issues that impede strategy implementation is the organizational change. He notes that managers are often trained to plan and not to execute strategies; the top managers are therefore always reluctant to soil their hands in the messy tasks of implementation. Strategy implementation always creates the need to manage change in complex organizational contexts (Kazmi, 2008).

Many of these areas of change are behavioural in nature and are therefore multifaceted and messy in nature. For instance, leadership style changes required to implement different kinds of strategies or the cultural changes to be brought about to facilitate new strategy implementation are intricate matters that call for careful handling (Kazmi, 2008)

Strategies are also connected to some kind of change and processes of renewal, and there is not a question of whether strategic changes will occur in organizations, but how and when (Höglund, 2015)

Change management is a systematic approach to dealing with change, both from the perspective of an organization and on the individual level. A somewhat ambiguous term, change management has at least three different aspects, including, adapting to change, controlling change, and effecting change. A proactive approach to dealing with change is at the core of all three aspects. (Wanner, 2013)

Changes might be big or small. They may involve evolution or revolution. They may be positive or negative. They may involve losing jobs or gaining jobs. The strategy might require new skills or actions. It might involve different areas of the business in different ways. It may be more externally or more internally focused. Change comes from different perspectives. 


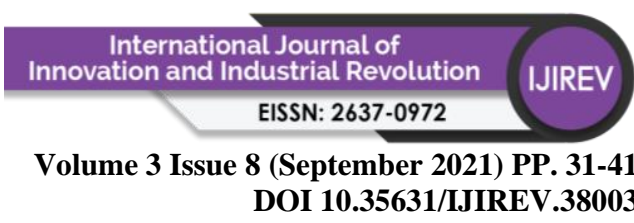

Responses to changes come from different perspectives and changes aren't going to be welcome in the same way. (Mckeown, 2016)

There are five distinct steps in effectively managing a change process - in doing project management: Defining the change objective, Developing a strategy and plans to achieve that objective, Creating a project management group to effect the change, Installing a control process to monitor progress, Managing the project by implementing the above four steps. Most change processes require a full-time management effort. In managing the change process towards its defined change objective, different skills located in different organizational units must be employed at different stages of the project. (Morris, 1983).

Project management in the age of digitization is associated with the hope of saving time and costs while increasing transparency. As a result, the expectation of stakeholders has grown to realize these positive effects. The introduction of new tools requires investment in technology, the adaptation of processes and standards, and the development of new knowledge. With the advancement of digitization, consistent management decisions and a strengthening of the project culture are required in order not to fall behind the competitors. (Ryba, 2017)

Generating advantage from new technologies requires new ways of thinking and operating so that we might truly capitalize on the potential that they can deliver. Too often we look at the new through the lens of the old and misappropriate old thinking onto new technology paradigms. Too often we focus on applying new technologies to existing operating challenges, Business processes or methods without rethinking how we might need to fundamentally redesign the way in which we need to work. (Perkin, 2020)

The implementation of strategies in organizations have therefore not been without challenges. Research has shown that more than $50 \%$ of the strategies fail at the implementation stage (Atkinson, 2006)

\section{Research Methodology}

This study adopted a descriptive survey design. It is used when the objective is to provide a systematic description that is as factual and accurate as possible and, in the case of this study, assesses the strategy implementation challenges faced in successful project management.

Descriptive designs only describe the phenomenon under study trying to establish a relationship between factors. In this study, the researcher tried to establish how various challenges affect project success and how to deal with them by effective and Smart implementation methodologies.

\section{Primary Data Collection}

Primary data for the study was collected using a questionnaire, which was formulated in order to achieve the objectives of the study. The use of a questionnaire was selected because it is a convenient way to obtain the responses of different managers working in different projectbased organizations and covers the various dynamics of Project management challenges. A questionnaire allows the researcher to obtain first-hand information. It also provides the opportunity to remain anonymous to promote a high response rate. 
Volume 3 Issue 8 (September 2021) PP. 31-41

DOI 10.35631/IJIREV.38003

Before the actual data collection, the researcher explained the purpose of the study in the introduction to the survey to enable easy understanding and facilitate adequate response.

\section{Data Analysis Results and Discussion}

The findings of this study suggest that project-based organizations are dealing with several challenges. Therefore, the top management of the Organization is requested to use Oversight criteria to mitigate them in project management.

Figure 1: Current Challenges in Project Management

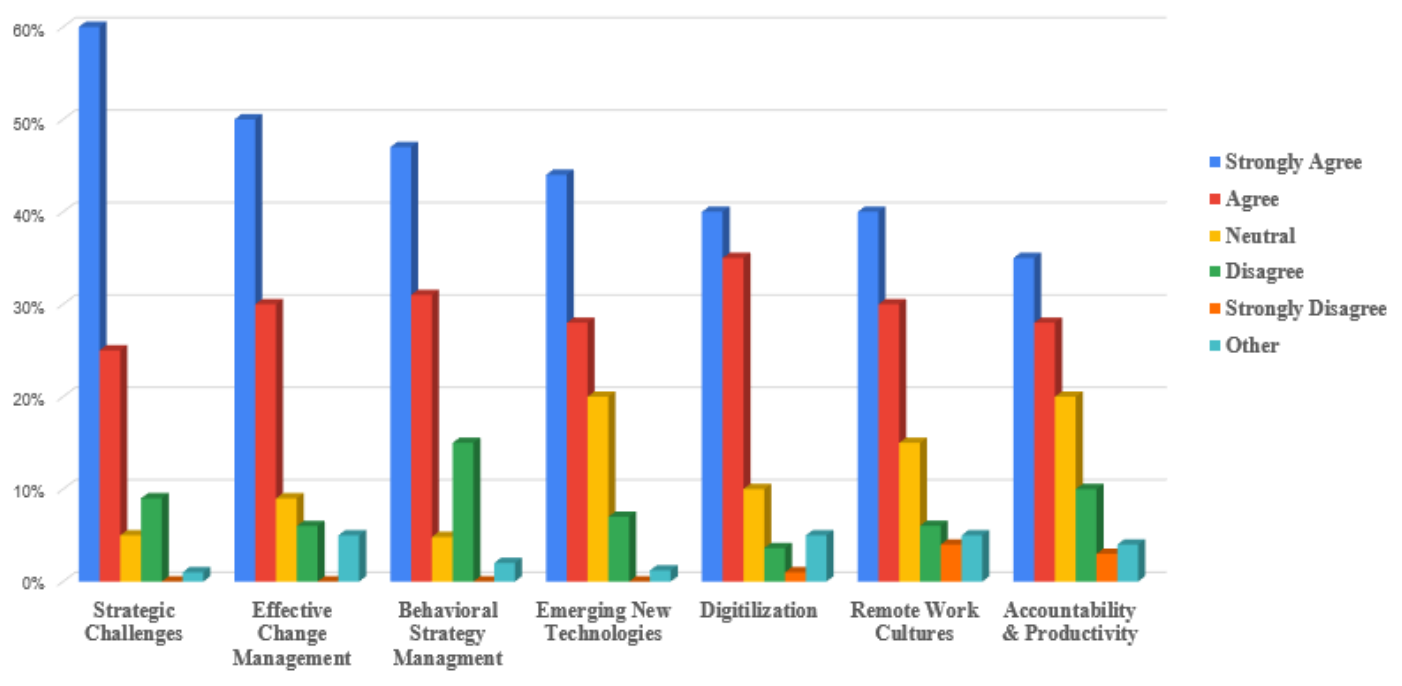

The bar chart in Figure:1 illustrates the Current Challenges in Project Management which shows the responses of 88 Number of different respondents' mangers from project-based organization working on different projects under different departments.

The response to each challenge area shows that Strategic Challenges are dominant among all other challenges. For which $60 \%$ of the respondents fully agreed, $25 \%$ agreed, $5 \%$ show a neutral response. However, $9 \%$ disagreed. there was $1 \%$ who gave other opinion, and no one was in total disagreement.

Effective Change Management turned out to be the second critical challenge, as $50 \%$ of respondents fully agreed, 30\% agreed, 9\% were neutral, $6 \%$ disagreed, 5\% gave another. opinion and 0\% Strongly disagreed.

Behavioral Strategy Management seemed to be the third challenging aspect, obviously, as $47 \%$ of the respondents fully agreed, $31 \%$ agreed, $5 \%$ were neutral, $15 \%$ disagreed, $2 \%$ offered another opinion and $0 \%$ strongly disagreed.

New Emerging Technologies, despite being promoted due to their innovative nature, ranked only fourth, with $44 \%$ of respondents fully agreed, $28 \%$ agreed, $20 \%$ neutral, $7 \%$ disagreed, $1 \%$ gave another opinion, and $0 \%$ strongly disagreed.

Digitalization was declared fifth, as $40 \%$ of respondents fully agreed, $35 \%$ agreed, $10 \%$ was neutral, $4 \%$ disagreed, $5 \%$ gave another opinion and $1 \%$ was strongly disagreed. 
Volume 3 Issue 8 (September 2021) PP. 31-41 DOI 10.35631/IJIREV.38003

Remote Work Cultures were placed in the penultimate position since $40 \%$ of the respondents strongly agreed, 30\% agreed, 15\% were neutral, $6 \%$ disagreed, $5 \%$ thought otherwise and $4 \%$ strongly disagreed.

Accountability and Productivity appeared as the least cause for concern for project managers, but it is important as 35\% of respondents strongly agreed, $28 \%$ agreed, $20 \%$ were neutral, $10 \%$ disagreed, $4 \%$ offered another opinion and 3\% strongly disagreed.

Further study showed that in strategic challenges as shown in Figure 2 there are the key dimensions to be focused more which are Effective Strategic Implementations, Strategy Planning, Agility (Iteration and Adaptation) and Strategic Challenges as Oportunities.

\section{Figure 2: Key Dimensions in Strategic Challenges}

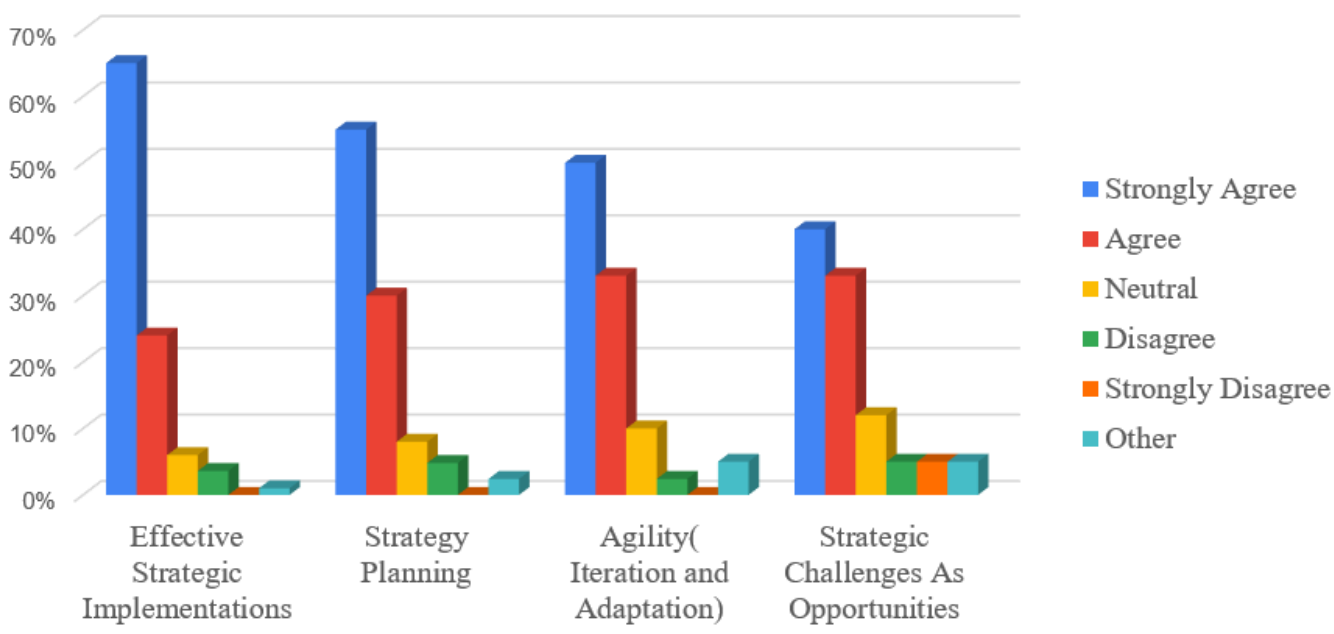

The responses collected from different managers are shown in Table: 1 for each strategic area and the trend shows that Effective Strategic Implementation is the main area to be considered followed by Strategic Planning and Agility (Iteration and Adaptation). However, the study also showed that current strategic challenges can be taken as opportunities for future improvements in the field of project management.

Table 1: Responses Against Each Strategic Dimension

\begin{tabular}{|c|c|c|c|c|}
\hline Responses & $\begin{array}{c}\text { Effective } \\
\text { Strategic } \\
\text { Implementations }\end{array}$ & $\begin{array}{c}\text { Strategy } \\
\text { Planning }\end{array}$ & $\begin{array}{c}\text { Agility } \\
\text { (Iteration and } \\
\text { Adaptation) }\end{array}$ & $\begin{array}{c}\text { Strategic } \\
\text { Challenges as } \\
\text { Opportunities }\end{array}$ \\
\hline Strongly Agree & $65 \%$ & $55 \%$ & $50 \%$ & $40 \%$ \\
\hline Agree & $24 \%$ & $30 \%$ & $33 \%$ & $33 \%$ \\
\hline Neutral & $6 \%$ & $8 \%$ & $10 \%$ & $12 \%$ \\
\hline Disagree & $4 \%$ & $5 \%$ & $2 \%$ & $5 \%$ \\
\hline $\begin{array}{c}\text { Strongly } \\
\text { Disagree }\end{array}$ & $0 \%$ & $0 \%$ & $0 \%$ & $5 \%$ \\
\hline Other & $1 \%$ & $2 \%$ & $5 \%$ & $5 \%$ \\
\hline
\end{tabular}


Volume 3 Issue 8 (September 2021) PP. 31-41

DOI 10.35631/IJIREV.38003

The findings also recognize the importance of good governance, the role of top management, team empowerment and strategic team alignment along with organizational culture, measures to address current project management challenges.

\section{Figure 3: Measures Taken to Deal with Project Management Challenges}

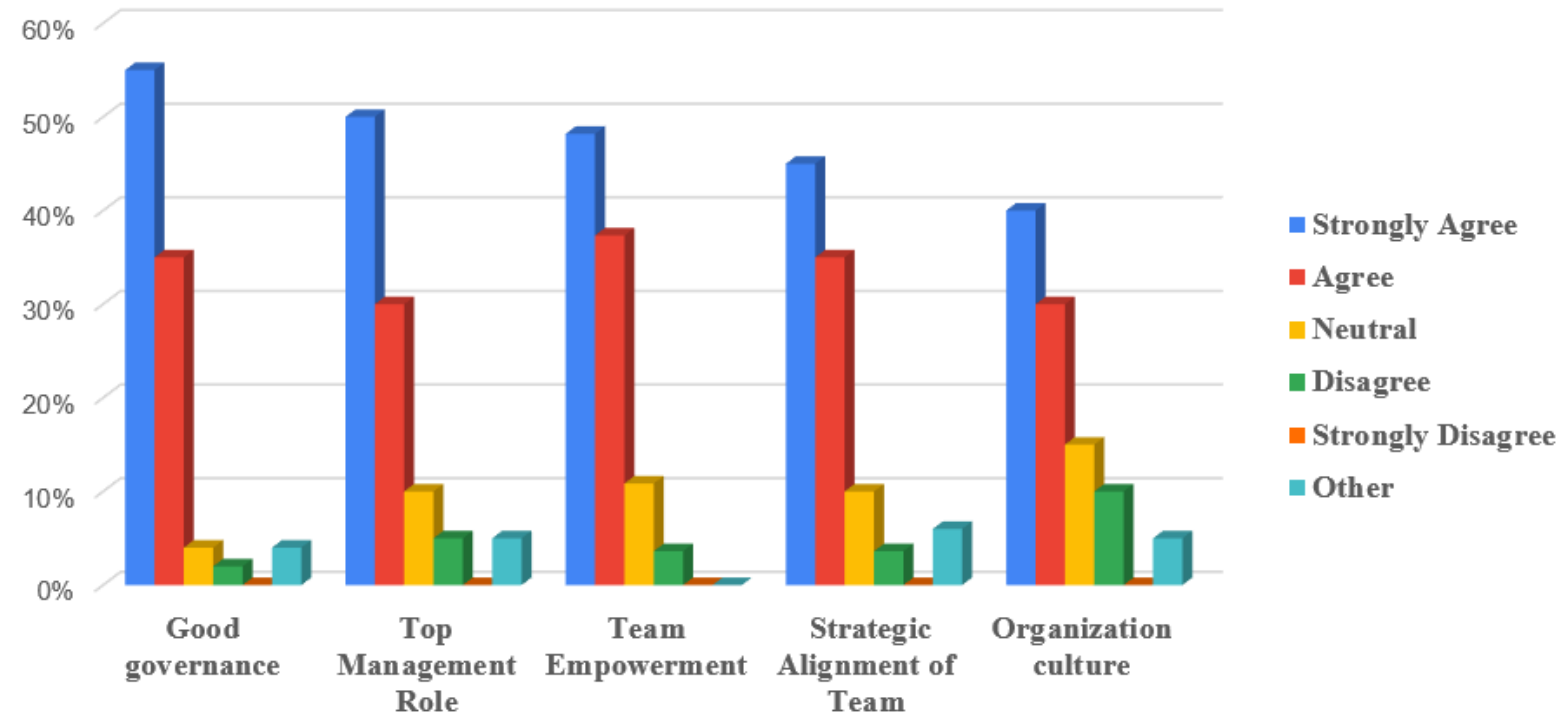

The top management of the organization, in coordination with the project managers, should develop the strategic management plan in the initial stage and, at the same time, should work on the policy of implementing an effective strategy. Mainly, the Project Manager deals with the challenges associated with strategic implementation in projects. Additionally, strategic thinking helps create a competitive environment for project managers. A strategy gives them the right direction between means and ends. In a way, the strategy must be competitive enough and must be linked to the actions and the implementation framework.

Furthermore, the study highlighted the importance of project management maturity at the project and organization level to establish strategies to focus on behavior management and monitor change management processes. Therefore, the project manager role goes so far as to state most of the lessons learned from experience during project execution. The strategies that organizations develop based on previous lessons learned and to verify weaknesses in existing processes and at the same time find room for improvement for future developments are considered more successful and sustainable.

To get to this point, project managers must help the organization create an environment in which employees want to become team members and work for the best of the team while staying long enough to make a difference. Undoubtedly, technological innovation represents a critical factor in managing team challenges by providing alternatives that will optimize the overall success of the project. This is evident in almost every exceptional organization trying to find the best approaches to satisfying employees.

In Project Management dealing with different behaviors of project teams effectively is therefore a challenge along with performance, efficiency and organizational best practices. Specifically, after the 2019 pandemic performance management, teamwork, productivity and accountability of those dealing with virtual teams become stern for Project Mangers. Project Copyright (C) GLOBAL ACADEMIC EXCELLENCE (M) SDN BHD - All rights reserved 


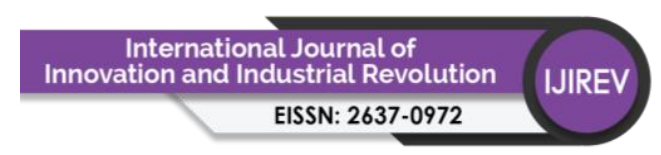

Volume 3 Issue 8 (September 2021) PP. 31-41

DOI 10.35631/IJIREV.38003

Manager must upgrade on new technology-based systems to address the challenges that they and their project teams face while working remotely. As remote working is the new standard and at the same time, technology has further revolutionized workplaces during a pandemic that has transformed working into a hybrid working model, where teams are both remote and in the office.

This study showed that organizations should focus on a clear directive for team empowerment that can provide competitive benefits for organizational goals and strategic objectives. A highly engaged, committed, trained, motivated and empowered team brings outstanding results of high productivity in projects. Empowering the team also creates responsibility for the results they must produce. Additionally, empowerment allows the team to share tasks with the project manager. Empowered project management teams must be strategically aligned with the organization's vision with a clear set of direction. This allows opportunities for project teams to learn and demonstrate skills and foster collaborations.

Based on the results of this review, future trends in project management are much different from what they have experienced in recent years. Hybrid project management will transform project-based organizational structures globally. Project teams will be diversified and virtual, so the focus of the project manager will be on communication \& mutual collaboration between stakeholders. Lean, Agile along with other emerging technologies and digitalization will be fully implemented in projects.

Future project managers are expected to have many different competitive skills to cope with current challenges in Project Management. Strategic thinking, Effective communication, Collaborative Approach, Comprehensive knowledge of Lean, Agile, Digital technologies, Dynamic Learning, strong leadership and New software skills are of prime importance. Eventually, technology skills will become increasingly important for the successful Project management.

Meanwhile, Digitalization in project processes along with all its challenges is presented as an opportunity as it aims to save time and human resource costs while transforming the dynamics of project management. It provides competitive advantages such as automation, optimization and advanced flexibility in projects.

Organization should access the changes in project management after all these transformations and should evaluate and implement the change management process in structured and planned way. Effective Change Management strategy is needed to mitigate the challenges in project management approach.

\section{Conclusion}

Organizations must focus on fostering the kinds of strategic thinking and actions that create and deliver competitive advantage. Transformation of existing project processes must focus heavily on Lean, Agile, and Digitalization. The organization should make the project managers aware of the new strategy and should involve them in the development of the strategy to encourage them and give them a sense of ownership in the implementation of the strategy in the execution of the projects. In order to turn project management challenges into opportunities, the organization must empower and train project managers together with their project teams for technological advancements and changes to adapt to new requirements. If the project 


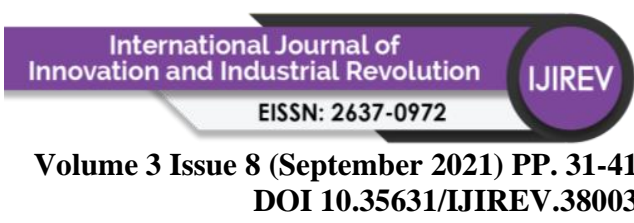

managers and his teams are sufficiently trained, they will take the changes as opportunities to put new techniques into practice for project success. In hybrid project management environment Project manager must combine with behavioral intelligence to deal with teams working. New strategies bring changes and organizations must evolve and transform with them. Change management processes should be adaptive and responsive. In addition, Effective Change Management is the solution to overcome the challenges that come with new strategic implementations and new technological advancements. This study provides a comprehensive empirical perspective on the strategic challenges along with other project management challenges faced by project-based organizations that are transforming the Project Management culture in recent times with enough recommendations to address them in order to obtain competitive advantages in successful projects.

\section{Recommendations}

Since strategic challenges define the competitive position of the organization going forward, project management organizations must develop the strategy based on the lessons learned along with the new requirements. Project Managers should formulate the execution strategies of the project aligned with the mission and vision of the organization. Effective strategies must be transparent in nature and use recent technology to track the progress of implementations. As future project management structures are being transformed with emerging technologies and digitalization, they can be seized as opportunities through Effective Change Management and team empowerment processes.

\section{Suggestions for Future Research}

This study was done for the challenges in Project Management facing in UAE Project Based Organizations. The study therefore recommends that similar studies should be replicated other organizations in the country to determine the current challenges in Project Management.

\section{Implication of the Study}

The strategist can use the recommendations to improve the development and implementation of their strategy in project-based organizations.

The management of project-based organizations can put the researcher's recommendations to improve the methodology to overcome internal strategic challenges.

The study can highlight areas for improvement that other researchers can use to conduct further research in the areas of Strategic Challenges in Successful Project Management.

\section{References}

AD., C. (1996). Strategy and structure. Cambridge (MA): MIT Press.

Ansoff, H. I. (1990). Implanting Strategic Management (2nd Ed),. New York: Prentice Hall. Atkinson, H. (2006). Strategy implementation: a role for the balanced scorecard?,Management DecisionVol. 44 No. 10, pp. 1441-60.

Glueck, F. a. (1984). Business Policy and Strategic Management. New Delhi: McGraw-Hill. Höglund, L. (2015). Strategic Entrepreneurship as Organizing Renewal in Established Organizations. . Lund: Studentlitteratur.

Hrebiniak, L. (2006). Implementing global strategies, European Management Journal,Vol.10 No. 4, pp. 392-5. 
Volume 3 Issue 8 (September 2021) PP. 31-41 DOI 10.35631/IJIREV.38003

Kazmi, A. (2008). Strategic Management and Business Policy , pp. 468-77. New: Tata McGraw-Hill.

Mckeown, M. (2016). The Strategy Book. Edinburgh: Pearson Education Limited.

Morris, P. W. (1983). Managing change through project management. Project Management Quarterly, 14(2), 60-70.

Pearce II, J. A. (2007). Strategic Management. McGraw - Hill,Irwin.

Perkin, N. (2020). Agile Transformation Structures,processes and mindsets for the digital age. London: Kogan Page Limited.

PMI USA. (2017). A guide to the project management body of knowledge (PMBOK guide) / Project Management Institute. 6th Edition. Newtown Square, Pennsylvania USA: Project Management Institute, Inc.

R.David, F. (2007). Strategic Management Concepts 11th edition. Pearson Education,Inc.,Upper Saddle River,New Jersey 07458.

Ryba, M. (2017, August 18th). Digital PMO - How does digitalization affect project management? Retrieved from Linkedin: https://www.linkedin.com/pulse/digital-pmohow-does-digitalization-affect-project-management-ryba

Wanner, M. F. (2013). Inegrated Change Mangement. PMI® Global Congress 2013-North America, New Orleans, LA. Newtown Square, . North America. 